\title{
Can the Marginal Productivity Theory of Distribution be TESTED?
}

\author{
Jesus Felipe $^{1}$ and John S.L. McCombie ${ }^{2}$
}

\begin{abstract}
This paper shows why attempts to test the neoclassical aggregate marginal productivity theory of distribution are inherently flawed. The use of constant-price value data and an underlying accounting identity mean that the close correspondence often found between the "output elasticities" of a putative aggregate production function and the relevant factor shares is a mere statistical artefact. Likewise, the results of estimating neoclassical labor demand functions must, for the same reason, always give spurious results.
\end{abstract}

JEL Codes: B41, E13, E25.

Keywords: marginal productivity theory of distribution, aggregate production function, accounting identity, statistical artefact.

\footnotetext{
${ }^{1}$ Asian Development Bank, Manila, Philippines

${ }^{2}$ University of Cambridge, UK

\section{Corresponding Author:}

John S. L. McCombie, Cambridge Centre for Economic and Public Policy, Department of Land Economy, University of Cambridge, 19 Silver Street, Cambridge, CB3 9EP, UK.

Email: jslm2@cam.ac.uk.
} 


\section{Introduction}

The degree of scepticism with which heterodox economists view the aggregate production function and the marginal productivity theory of distribution seems puzzling to many mainstream, or neoclassical, economists. After all, the aggregate production function is surely an uncontroversial concept, pace Joan Robinson (1953-54). The micro-production function is merely a short-hand way of expressing the various complex production relationships that exist between output and the various inputs. This is a simplified representation of a technological or engineering production relationship. It is mostly uncontroversial and most economists accept this concept. While neoclassical economists acknowledge that there are certain problems in moving from the micro to the macro level, they argue that these are no more serious than those that exist in many other branches of applied macroeconomics. Solow (1957), for example, draws a comparison between the problems of aggregating production functions and those involved in the consumption function. In fact, macroeconomics is, by definition, about aggregate relationships. Most heterodox economists accept, however, that the aggregation of micro production functions into an aggregate production is very problematic. The Cambridge capital theory controversies did, neoclassical economists concede, raise some interesting points of logic concerning the measurement of capital. However, the interpretation of the results by the Cambridge, UK, school of thought as having profound methodological implications for economics (Harcourt, 1976) is, in retrospect, dismissed as merely "a playing out of ideological games in the language of analytical economics" (Solow, 1988, p.309).

The neoclassical marginal productivity theory of distribution is dependent on the existence of a well-behaved micro-production function, the assumptions of profit maximisation and perfectly competitive markets. It may well be that, in reality, 
markets are oligopolistic and that the wage bargain is influenced by sociological factors. Nevertheless, it is often held that the assumption of perfectly competitive markets is a useful starting point. Notwithstanding the inherent aggregation problems, the concept of the aggregate production function, ever since the work of Cobb and Douglas (1928), has generally, but not always, stood up well to empirical testing. (Time-series data give poorer statistical fits than cross-sectional data. The reason for this is discussed below.) Moreover, indirect tests of the aggregate marginal productivity theory of distribution have likewise generally passed with flying colours (Hamermesh, 1993). Thus, under an instrumentalist methodology (Friedman, 1953) where the realism of the assumptions is irrelevant and what matters is the predictive ability of the model, both the aggregate production function and the marginal productivity theory of distribution can be considered to be convincing representations of the real world.

Critics such as the Marxists and the Post-Keynesians, nevertheless, see the marginal productivity theory of distribution as being "ideological". How could it be otherwise? As Kuhn (1970) long ago argued, paradigm choice is ultimately due to subjective factors. Consequently, it cannot be divorced from ideology, broadly defined. As far as the marginal productivity theory is concerned, as John Bates Clark (1899, p.v) memorably wrote, "[i]t is the purpose of this work to show that the distribution of income to society is controlled by a natural law, and that this law, if it worked without friction, would give to every agent of production the amount of wealth which that agent creates". While this statement does not imply that this is what every agent ought to get, it is often implicitly assumed that this is the case. The critics also argue that the widespread use of the marginal productivity theory rules out, tout court, any serious consideration of other theories of the determination of the wage and profit rates. For example, changes in factor shares, such as those that have occurred over the last decade in the advanced countries, 
have, in the neoclassical schema, to be explained in terms of the aggregate elasticity of substitution differing from unity, or in terms of changes in the technological parameters of the production function. Douglas (1976, p. 914) summarized his conclusions from his work in estimating production functions as follows:

A considerable body of independent work tends to corroborate the original Cobb-Douglas formula, but more important, the approximate coincidence of the estimated coefficients with the actual shares also strengthens the competitive theory of distribution and disproves the Marxian.

A problem, as will be shown, is that it is not possible to test the marginal productivity theory at the level of the individual worker, and so recourse is made to the putatively successful use of aggregate data. Two empirical results using these data are often advanced in support of the marginal productivity theory. The first is that, ever since the seminal work of Cobb and Douglas (1928), it has often been found that the estimates of the "output elasticities" of the aggregate production function are empirically in accord with the values of the relevant factor shares in national income. These results are precisely those predicted by the marginal productivity theory of distribution. Fisher (1971, p. 305) commented that Solow once remarked to him that "had Douglas found labor's share to be 25 per cent and capital's share 75 per cent instead of the other way around, we would not now be discussing aggregate production functions". Secondly, most estimates of the demand for labor function, where the latter is likewise derived from the aggregate production function and the marginal productivity conditions, also give good statistical fits, with the estimated coefficients close to their expected values (see Hamermesh, 1993, for a review of the evidence). The key finding is that there is an 
inverse relationship between the demand for labor and the wage rate, which is again a prediction of the marginal productivity theory of distribution.

However, it will be shown in this paper that these results, as a matter of logic, cannot be interpreted as providing any support for the marginal productivity theory of distribution. This is because the use of aggregate data involves an underlying accounting identity which robs these tests of any behavioural content. The identity is that value added is definitionally equal to the sum of labor's total compensation and total profits. The accounting identity critique is more general than this as it does not just apply to the marginal productivity theory of distribution. It renders the concept of the aggregate production function, per se, untestable, as statistical estimates of its parameters merely reflect a mathematical transformation of the linear accounting identity.

The fact that the inverse relationship between the level of employment and wage rate has no behavioural content is either not appreciated, or totally ignored, in both the applied and theoretical neoclassical literature on the marginal productivity theory of distribution. One possible reason for this is that it is not immediately apparent that the labor demand function, usually expressed in terms of log-levels and including a time trend purportedly to capture technical progress, is simply an isomorphism of the accounting identity, albeit sometimes misspecified. This paper shows why this must always be the case and illustrates the proof with regression analysis. Before elaborating on this argument, we first briefly rehearse the standard neoclassical theory behind the marginal productivity theory of distribution. 


\section{The Microeconomic Basis of the Marginal Productivity Theory of Distribution}

Standard neoclassical production theory specifies the production function in physical terms and it is, therefore, a microeconomic concept. It is, as we noted above, a technological relationship with the parameters such as the output elasticities and the elasticity of substitution reflecting the underlying engineering or technological relationships, broadly defined. Given the physical basis of the notion of a production function, it is useful to cite, at some length, Ferguson (1971, p.250), who wrote what was for many years the definitive study of neoclassical production theory (Ferguson, 1969). Ferguson argued that, in his book, he

assumed a [microeconomic] production function relating physical output to the physical inputs of heterogeneous labor, heterogeneous machines, and heterogeneous raw materials. ... Assuming variable proportions, each physical input has a welldefined marginal physical product. If profit maximization is also assumed $(\ldots)$ each entrepreneur will hire units of each physical input until the value of its marginal physical product is equal to its market determined and parametrically-given input price. In essence, this is what I called the neoclassical, or marginal productivity, theory of input pricing. (Ferguson, 1971, p.250, emphasis added)

The formal theory of the marginal theory of factor pricing is now so standard that it appears uncritically in all introductory microeconomic textbooks. Nevertheless, it is useful briefly to recapitulate this analysis. We start with the simplest specification of a microeconomic production function, given by: 


$$
Q=A f(K, L)
$$

where $Q$ and $K$ are the numbers of physical units of output and capital and $A$ measures the efficiency of production, or the level of technology. $L$ is the number of workers employed. Strictly speaking, $K$ and $L$ should be flows of their services (identical machine-hours and man-hours), but it is usually assumed that these are directly proportional to their respective stocks. This specification is essentially that of the representative firm or organization, but even here the simplification is made that the diverse physical types of capital can be measured in homogeneous units. ${ }^{3}$

The following relationship follows from Euler's condition for a linear homogeneous equation:

$$
Q=f_{K} K+f_{L} L
$$

where $f_{k}$ and $f_{L}$ are the marginal productivities of capital and labor, respectively, once again measured in physical terms. To express these in money terms, equation (2) is multiplied by the price per unit of output (£s per unit) to give:

$$
p Q=p f_{K} K+p f_{L} L
$$

\footnotetext{
${ }^{3}$ Ideally, materials should be included as an input, although it is generally implicitly assumed by neoclassical economists that abstracting from these does not affect the argument. However, as Moseley (2015) has pointed out, it is not possible to increase output solely by increasing capital or labor. Increases in either of these inputs require an associated increase in materials and hence the concept of the marginal productivity of these factors of production also becomes incoherent on these grounds.
} 
If factors were paid their marginal products, then $p f_{K}$ equals $\rho$, the rental price of capital, and $p f_{L}=w$, the wage rate. Equation (3) shows that the payments to the two factors of production exactly exhaust the product.

In the case of the ubiquitous Cobb-Douglas production function, namely,

$$
Q=A K^{\alpha} L^{\beta}
$$

the well-known result is obtained that, under the assumption of constant returns to scale (i.e., $\beta=1-\alpha$ ), capital's share in total income, $a$, equals its output elasticity, $\alpha$, and, similarly, labor's share (1-a) equals its output elasticity $(1-\alpha)$. These relations are given by equation (5):

$$
\frac{\rho K}{p Q} \equiv a \equiv \alpha \text { and } \frac{w L}{p Q}=(1-a)=(1-\alpha)=\beta
$$

As we shall see, this gives the basis for an indirect test of the marginal productivity theory using aggregate constant-price value data.

The question of the direction of causation (and indeed whether or not there is one) between the marginal product and the wage rate has been discussed by Blaug (1980, p. 194). Blaug is a methodologist in the Popperian tradition who is also skeptical of the use of the marginal productivity theory, although for different reasons than those discussed in this paper. He argued that "[t]he equality of factor prices and marginal products is an equilibrium solution of a set of simultaneous equations, and it seems pointless to select 'marginal productivity' as a sort of prime 
mover. For this and other reasons, it would be a great advantage if the phrase 'marginal productivity theory of distribution' were banished from the literature".

It is difficult to see the rationale underlying Blaug's argument, which seems to be merely one of semantics. At the aggregate level, the supply curve of labor and the aggregate marginal revenue product curve determine the nominal wage which the perfectly competitive firm takes as a datum. The firm then sets the level of employment where the wage rate equals the marginal revenue product of labor. But, nevertheless, what the worker receives is the marginal physical product of the marginal worker (multiplied by the price of this homogeneous output). From the firm's point of view, and that of the individual worker, the wage (and the level of employment) is determined by the technological conditions of production. In this paradigm, as we have noted, there is no room for the wage rate to be determined by, say, the bargaining power of capital versus labor or other sociological norms.

It is true, nevertheless, as Blaug (1980, p. 195) reminds us, that this is really a theory of factor pricing rather than of distributive shares. The latter can be influenced by, for example, the redistributive effects of taxation. However, it is a theory of the pre-tax factor shares and this is what is tested. Moreover, as we noted in the Introduction, there is a tendency for the marginal productivity theory to be treated as having normative connotations a là John Bates Clark. It is the hallmark of neoclassical theorising to close many theoretical models by uncritically assuming that markets are perfectly competitive; that there exists a well-behaved (aggregate) production function; and that factors are paid their marginal products. Any deviation of factor prices from marginal productivities will lead to a misallocation of resources, i.e., to allocations that are not Pareto optimal. Of course, there is no reason to suppose that a Pareto optimal outcome will maximize social wellbeing. 
Blaug also questions the reason why anyone should wish to be concerned with, and to predict, relative factor shares. It is true, he argues, that by definition the share of wages equals the wage rate divided by the average product of labor. In other words, $(1-a)=w /(p Q / L)=w L / p Q$ where $(1-a)$ is labor's share, $w$ is the wage rate in money terms, $L$ is employment, $Q$ is physical output and $p$ is the price of output. (Recall that we are dealing with the microeconomic theory of factor pricing so $p$ is measured in, say, £s per unit of output). But, Blaug continues, the average product of labor is not a behavioural variable in neoclassical analysis; economic actors do not maximize it. However, this overlooks the well-known result discussed above that, if factors are paid their marginal products and the usual neoclassical assumptions hold, then the technologically determined output elasticity of labor will equal labor's factor share. This correspondence has been taken (at the aggregate level) as a test that factors are paid their marginal products (Douglas, 1948, 1976).

\section{Microeconomic Tests of the Marginal Productivity Theory}

Given the expressed need for rigorous microfoundations by neoclassical macroeconomists, it is ironical that it is doubtful whether, even in principle, the marginal productivity theory could be tested using microeconomic data. The first problem is whether or not the output of an individual (marginal) employee can be expressed in physical units. The difficulty is that for many, or indeed nearly all, occupations, there simply is no independent measure of output. Think, for example, of the government, financial, education, and health sectors, etc. Indeed, it is easier to try to think of occupations where this is the case. Where there is no independent measure, the value of output is often the deflated wage bill with an arbitrary mark-up for differences in productivity. To use such data to test the 
marginal productivity theory would be a classic case of circular reasoning, as we will show below.

Moreover, with the substantial degree of the division of labor in modern society, the output (however measured) of one employee is likely to be heavily dependent on that of other workers, often with very different skills and job specifications. Even in manufacturing, the value of output of a particular worker is ill defined. How do you measure the physical product of, say, a worker who fits engines in a car assembly plant on the production line? Is it the number of engines fitted per week or per month by the marginal worker? But how is that valued and who is the marginal worker? How is the output of a chief executive officer (CEO) of a major financial institution measured? To say that his or her salary is that which the market for CEOs determines begs the question. What market? The salaries of CEOs are normally determined by remuneration boards comprising other CEOs or high earners and a large element of self-justification is likely to enter into the decision. A case could be made that the marginal productivity of many CEOs of financial institutions, while not being capable of being precisely measured has, in recent years, actually been negative. Again, is the fact that academic salaries are uniformly lower in the UK than in the US evidence that the marginal products of the former are lower?

Other, perhaps less serious problems, have been eloquently discussed by Thurow (1975, pp. 211-230) in his "do-it-yourself guide to marginal productivity" and by Blaug (1980, pp. 199-201). They are less serious because they implicitly assume that the output of a 'group' of employees over a 'period of time' can actually be measured and focus on the difficulty of the determination of the group or the period of time. Thurow and Blaug also discussed the difficulties of testing this theory when 
there are economies of scale and imperfectly competitive markets present, which pose further problems for the marginal productivity theory.

\section{Macroeconomic Tests of the Marginal Productivity Theory of Distribution.}

Given the virtual impossibility of testing the marginal productivity theory using physical (i.e., microeconomic) data, the only alternative is to use aggregate data. This means, by definition, using constant-price value data instead of physical data.

A major problem, to which we alluded above, is how to generalize these microeconomic relationships to more complex production processes. Franklin Fisher (2005, p. 490) who has done more work than most on the aggregation problem is firmly of the opinion that it simply cannot be done.

Even under constant returns, the conditions for aggregation are so very stringent as to make the existence of aggregate production functions in real economies a non-event. This is true not only for the existence of an aggregate capital stock but also for the existence of such constructs as aggregate labor or even aggregate output.

One cannot escape the force of these results by arguing that aggregate production functions are only approximations. While, over some restricted range of the data, approximations may appear to fit, good approximations to the true underlying technical relations require close approximation to the stringent 
aggregation conditions, and this is not a sensible thing to suppose.

Such reservations are normally simply ignored in both introductory and the more advanced microeconomics and macroeconomics textbooks. Where they are mentioned, the implications are minimized. For example, Esterin and Laidler (1995, p. 134) assert, in their microeconomics textbook, without any justification that "the results of the two input/one output special case are both useful and often capable of being generalized, and are therefore well worth the reader's attention".

An argument that is often implicitly made is that as regression analysis gives good statistical fits with plausible estimates, this justifies the usefulness of the aggregate production function and the aggregate marginal productivity theory of distribution. Consequently, the appropriate procedure is to use aggregate data and to test empirically the theory.

Cobb and Douglas (1928) used aggregate data faute de miuex and they were the first to estimate an aggregate production function, the results of which, especially using cross-industry data, seemed to give a remarkably good statistical fit. This, and subsequent studies, have been taken as confirming (or not refuting) the existence of the aggregate production function, notwithstanding all the associated aggregation and other problems (differences in $X$-efficiency, etc.). It is useful to consider their results in detail, not just for historical interest, but because they determined the methodology that has been adopted in countless subsequent studies, although with ever increasing sophistication in the estimation techniques. 
The problems raised here with respect to their work apply equally to all subsequent studies. $^{4}$

Cobb and Douglas (1928) tested the aggregate marginal productivity theory of distribution indirectly by determining the degree of correspondence between the output elasticities and factor shares. They set out the above first-order conditions (equation (5)) at the microeconomic level in their seminal paper, although they assumed that they applied equally at the aggregate level. ${ }^{5}$ As they had to use aggregate data, they implicitly assumed that constant price value added $(V)$ is, in fact, identical to the "volume of physical production" (p. 140), and the deflated value of the capital stock is likewise synonymous with a physical measure. This legerdemain is far from innocuous as we shall show below.

They estimated equation (4) in logarithmic form with data for the US manufacturing sector over the period 1899-1922 and found a very close statistical fit with an $R^{2}$ of over 0.9 . However, they imposed the constraint that the sum of the elasticities equalled unity, i.e. they assumed constant returns to scale. Subsequently, they freely estimated the elasticities and found that it did not make any significant difference (McCombie, 1998). The estimates of the sum of the elasticities did not differ greatly from one. These results should have been seen as a remarkable

\footnotetext{
${ }^{4}$ The initial paper of Cobb and Douglas (1928) was received with some hostility on econometric grounds by, for example, Mendershausen (1938).

${ }^{5}$ Blaug (1980, p. 194) attributes the argument that the distribution of income may be explained by the marginal productivity theory to Hicks (1932) in his Theory of Wages. However, it had been clearly anticipated by Cobb and Douglas (1928).
} 
result given the crudeness of the data. ${ }^{6}$ The results were interpreted by them as confirming the marginal productivity theory of distribution. This was because they found that the estimate of labor's output elasticity (1- $\alpha)$ was 0.75 compared with the NBER's average figure of 0.74 over the period 1909-1918. This paper was responsible for initiating a plethora of subsequent empirical studies that has persisted until today. Such was its importance that it was named as one of the twenty most influential papers published in the American Economic Review during the last century (Arrow, et al., 2011).

It is, therefore, ironical that Cobb-and Douglas's original results do not stand up to scrutiny. First, the results are dependent upon the inclusion of a few extreme years at the end of their sample. When these are removed, or a rolling regression is undertaken, the results are shown to be far from robust and the factor shares do not equal the estimates of the relevant output elasticities. The estimate of the output elasticity of capital is often negative and/or statistically insignificant. Secondly, if a time trend is included to capture the effect of technical change (which is now a standard procedure), the regression results also collapse.

Douglas (1934) appeared to have realized these problems and noted that they occurred with a subsequent time-series regression using data for Massachusetts.

Possibly because of this, in the 1930s, Douglas switched away from time-series estimation and, with a number of colleagues, estimated numerous production functions using cross-section industry data. These uniformly confirmed that the estimated output elasticities were close to the factor shares. The poor results using time-series either went unnoticed, or were quietly forgotten.

\footnotetext{
${ }^{6}$ The estimates of the capital stock were abandoned in 1920-21 for many years because of their perceived unreliability (Douglas, 1976, p. 911).
} 
In his retrospective look at his cross-sectional regression results for the 1930 s, Douglas (1976) presented some more recent estimates using cross-industry data for Australia. These are reported in Table 1.The results are very close to those obtained using cross-sectional data for the earlier periods. It can be seen that labor's share, $(1-a)$, is almost identical to its output elasticity, $\beta$, and the production function exhibits constant returns to scale, or as near as makes no difference $(\alpha+$ $\beta=1$ ). The former is what the aggregate marginal productivity theory predicts.

Table 1 Production Function for Australian Manufacturing, 1956, 1957, 1964-68

\begin{tabular}{|l|l|l|l|l|l|l|l|}
\hline $\begin{array}{l}\text { Fiscal } \\
\text { Year }\end{array}$ & $N$ & $\alpha$ & $S E$ & $\beta$ & SE & $(1-\mathrm{a})$ & $\alpha+\beta$ \\
\hline 1956 & 159 & 0.365 & 0.03 & 0.615 & 0.02 & 0.602 & 0.980 \\
\hline 1957 & 159 & 0.381 & 0.03 & 0.610 & 0.02 & 0.581 & 0.991 \\
\hline 1964 & 163 & 0.396 & 0.03 & 0.595 & 0.03 & 0.527 & 0.991 \\
\hline 1965 & 161 & 0.414 & 0.03 & 0.576 & 0.03 & 0.530 & 0.990 \\
\hline 1966 & 161 & 0.434 & 0.03 & 0.562 & 0.03 & 0.528 & 0.996 \\
\hline 1967 & 160 & 0.425 & 0.03 & 0.575 & 0.03 & 0.517 & 1.000 \\
\hline 1968 & 160 & 0.456 & 0.03 & 0.536 & 0.03 & 0.514 & 0.992 \\
\hline & & & & & & & \\
\hline
\end{tabular}

Notes: $N$ is the number of observations, $\alpha$ and $\beta$ are capital's and labor's output elasticity respectively. SE is the standard error of the coefficient, $(1-a)$ is the share of labor in total output. Source: Douglas (1976), Tables 4 and 5, pp. 912 and 913.

While, of course, more flexible specifications of the aggregate production function with more sophisticated econometric techniques are now used, this indirect method 
of testing the marginal productivity theory has continued. It is seen as uncontroversial and the marginal productivity theory is now the standard orthodox basis for explaining the distribution of national income between capital and labor in introductory textbooks. ${ }^{7}$

Mankiw and Taylor (2008, p.69), for example, assert that "[ $f]$ otal output is divided between the payment to capital and the payments to labor depending on their marginal productivities" (emphasis in the original). "We can now verify that if factors earn their marginal products, then the parameter $\alpha$ tells us how much income goes to labor and how much goes to capital" (p. 71). "The Cobb-Douglas production function is not the last word in explaining the economy's production of goods and services or the distribution of income between capital and labor. It is, however, a good place to start" (p.71). The instrumentalist view of the aggregate production function is explicitly propounded by Hoover (2012, p. 326). "Instead of trying to figure out the properties of the aggregate production function from first principles, our strategy will be to start with a conjecture that the economy can be described by a particular production function, one that shares important properties with microeconomic production functions. We will then test our conjecture empirically. If it seems to describe the data well, we shall be satisfied that it provides a useful approximation". He continues that "The approximate constancy of the labor share confirms the prediction of our model and provides a good reason to take the Cobb-

\footnotetext{
${ }^{7}$ As Kuhn (1970) shows, the textbooks are important as they inculcate in the students what is assumed in the paradigm to be uncontroversial. Kuhn uses the term pseudoparadigmatic assumption to be a relationship that has been subject to repeated testing, but which has become so central to the paradigm that it has now become irrefutable by fiat. The aggregate production function and the marginal productivity theory of distribution have achieved this status in neoclassical economics.
} 
Douglas production function as a reasonable approximation of aggregate supply in this economy" (p. 330).

However, the use of value added in the estimation of the aggregate production function is not innocuous. In fact, pace Mankiw and Taylor (2008) and Hoover (2012), inter alios, it precludes the possibility of rejecting the null hypothesis that the output elasticities equal the factor shares and of estimating the parameters of a "true" production function, as we shall now demonstrate.

In neoclassical (micro) production theory, the value of output is $p Q$, but as the statistical estimation is in aggregate terms, the nominal value of output of an industry at time $t$ is given by $P_{t} \Sigma p_{i 0} Q_{i t}=P_{t} V_{I N D, t, 0}$, where $P$ is the price deflator not the price. The subscript $t$ denotes the year, 0 is the base year, $i$ is the firm and IND denotes the industry (as we are dealing with cross-industry data for the moment). $V_{I N D, t, 0}$ is the value of industry output in time $t$ measured in the base-year prices.

In constant price terms we have an accounting identity:

$$
V_{i} \equiv w_{i} L_{i}+r_{i} J_{i}
$$

where $w$ is the wage rate, $r$ is the rate of profit (a pure number) and $J$ is the constant price value of the aggregate capital stock. It should be emphasized that this holds for all states of competition, and most importantly, even if an aggregate production function does not exist.

However, equation (6) may be rewritten as a functional form that looks like a CobbDouglas relationship. (The argument is more general than this and applies to all 
specifications of aggregate production functions.) This may be shown in a number of equivalent ways. Simon and Levy (1963), for example, expand both equation (6) and the Cobb-Douglas relationship, equation (4) but with constant returns to scale, by a Taylor-series expansion and show that they are formally equivalent.

A Taylor-series expansion of the Cobb-Douglas production function given by equation (4) but with constant returns to scale imposed around $V^{\prime}, J^{\prime}$ and $L^{\prime}$ gives:

$$
V=V^{\prime}+\alpha \frac{V^{\prime}}{J^{\prime}}\left(J-J^{\prime}\right)+(1-\alpha) \frac{V^{\prime}}{L^{\prime}}\left(L-L^{\prime}\right)
$$

The accounting identity is given by

$$
V \equiv V^{\prime}+r\left(J-J^{\prime}\right)+w\left(L-L^{\prime}\right)
$$

From equations (7) and (8), it can be seen that $\alpha V^{\prime} / J^{\prime}=r$, so that $\alpha=a=r J^{\prime} / V^{\prime}$. Likewise, $(1-\alpha)=(1-a)=w L^{\prime} / V^{\prime}$.

Two observations are in order here. First, because the accounting identity is true by definition, it follows that the sum of the coefficients of the Cobb-Douglas function must equal unity. Secondly, it has been argued that this merely demonstrates the equilibrium condition that the total cost curve will be at a tangent to the production function. But this assumes that there is a well-defined aggregate production function. In fact, the above argument shows that the "causation" runs the other way. The accounting identity will by definition give a good approximation to the Cobb Douglas function even when though no well-behaved aggregate production function exists. (At the risk of repetition, this conclusion holds for any putative production function, not just the Cobb-Douglas.) As Simon and Levy (1963, p.94) 
put it, "the existence of a fitted Cobb-Douglas [function] with a value of [1- $\alpha$ ] in agreement with the actual $[1-\alpha]$ does not imply that the underlying production function is truly Cobb-Douglas. In fact, we expect this agreement when the true function is given by [6]". Shaikh (1974) extends the argument to the use of timeseries data. See Felipe and McCombie (2013) for a detailed discussion of the critique and for the problems it poses for a large number of neoclassical macroeconomic models.

As the linear income identity exists for any underlying technology, we can be confident that all that the regression estimates are picking up is simply the identity. The fact that a good fit to the Cobb-Douglas relationship is found implies nothing, per se, about such technological parameters such as the elasticity of substitution.

We may show this argument in another way. Assuming a continuum of firms of different sizes and taking the total differential of equation (6) and integrating, we obtain:

$$
\begin{aligned}
& V_{i} \equiv r_{i} J_{i}+w_{i} L_{i} \\
& \equiv C r_{i}^{a} w_{i}^{(1-a)} J_{i}^{a} L_{i}^{(1-a)}
\end{aligned}
$$

$C$ is the constant of integration and is equal to $a^{-a}(1-a)^{-(1-a)}$. (We have dropped the subscript $i$ on the factor shares for notational convenience.) Note that equations (9.1) and (9.2) are formally identical, hence the use of the $\equiv$ symbol. However, when we come to estimate the production functions using, in this case cross-industry data, it becomes an approximation because the factor shares and $w$ and $r$ are likely to differ to some extent between firms. 
But if the wage rate and the rate of profit are roughly constant in the data set and the factor shares do not greatly differ then estimating:

$$
\ln V_{i}=c+b_{1} \ln J_{i}+b_{2} \ln L_{i}
$$

will give a very close statistical fit with the estimates of $b_{1}$ and $b_{2}$ very close to the aggregate factor shares, even though no aggregate production function exists. (Throughout this paper, $c$ is taken as a generic constant.)

This argument is illustrated in Figure 1. Assume that we have a firm whose constant-price value of productivity and capital-labor ratio is given by point $A$ and lies on the accounting identity given by the line $a b$. In the neighbourhood of $A$, as we have shown, a Taylor-series expansion shows that the Cobb-Douglas functional form will be an isomorphous transformation of the identity. Assume for expositional ease that the wage rate and the rate of profit are constant so that, for different firms, all the observations lie on the same accounting identity. In fact there is likely to be some dispersion so there will be a number of linear accounting identities, but we shall ignore this for expositional purposes. Moreover, we assume that the variation in $w$ and $r$ is small compared to the variations in productivity and in the capital-labor ratio. It can be seen that if we mistakenly estimate a single Cobb-Douglas production function, the best fit will be given by the dotted line, which will give a close, but not perfect, fit. Simon (1979. p.466) showed that even if the variation in the capital-labor ratio that exceeds anything found in reality, the error in using the Cobb-Douglas rather than the accounting identity is, on average, about 5 per cent.

[Figure 1 about here] 
The argument follows through for time-series data, but now a linear time trend $(\lambda t)$ is usually introduced to capture the growth rates of wages and the rate of profit:

$$
\ln V_{t}=c+\lambda t+b_{1} \ln J_{t}+b_{2} \ln L_{t}
$$

However, as with Cobb and Douglas's original data, often the statistical fit is very high but the estimated coefficients are statistically insignificant or implausible (e.g., negative). This is because of the relatively large cyclical variation of the wage rate and, especially, the rate of profit. Consequently, proxying those by a linear time trend leads to a serious misspecification error. If either a more complex time trend is included that closely tracks them, or if the capital stock is adjusted for capacity utilization (which will reduce the cyclical variation in the rate of profit), the estimated coefficients will again be very close to the factor shares, but solely because of the accounting identity. The results below use Cobb and Douglas's (1928) original data with the last years omitted (see Felipe and Adams, 2005, Felipe and McCombie, 2013, p.157). Their inclusion gives poorly determined coefficients that are not reported here. Now, a more complex time trend $\left(\tau_{t}\right)$ is introduced that closely approximates to $a \ln r_{t}+(1-a) \ln w_{t .}^{8}$ It can be seen that the estimates of the parameters closely approximate the identity.

$$
\ln V_{t}=0.023 \tau_{\mathrm{t}}+0.756 \ln L_{t}+0.246 \ln J_{t} \quad R^{2}=0.977 ; D . W .=1.76
$$

Consequently, the degree of correspondence between the estimates of the "output elasticities" and the factor shares cannot, even in principle, constitute a test of the marginal productivity theory of distribution. The factor shares and the output

\footnotetext{
${ }^{8}$ The time trend is given by $\tau(t)=\left[\sin \left(t^{5}\right)+\cos \left(t^{4}\right)-\cos \left(t^{2}\right)-\sin \left(t^{2}\right)\right]$
} 
elasticities are, as Phelps Brown (1957, p.557) cogently put it, merely "two sides of the same penny".

\section{Estimating the Neoclassical Labor Demand Function}

Another putative way of indirectly testing the marginal productivity theory is to estimate an aggregate neoclassical labor demand function, which is derived from the marginal productivity conditions and the aggregate production function. Again, the aim is to see if the estimate parameters are in accord with what the theory suggests (Hamermesh, 1993). There are a number of different specifications, but for simplicity we shall concern ourselves here with only the Cobb-Douglas production function where output is held constant. (The following discussion draws on Felipe and McCombie, 2009) Under the usual neoclassical assumptions and cost minimisation, the demand for labor function in this case is given by:

$$
\ln L_{t}=-\ln A_{0}+\alpha \ln ((1-\alpha) / \alpha)+\ln Q_{t}-\alpha \ln w_{t}+\alpha \ln \rho_{t}-\lambda t(12)
$$

where $\rho$ is again an index of the rental price of capital (which can be proxied by the rate of profit) and $\lambda$ is the rate of technical progress. (See, for example, Clark and Freeman, 1980 and Hamermesh, 1993.)

If we were to estimate the identity using time-series data, we should expect the estimates to be:

$$
\begin{aligned}
& \ln L_{t} \equiv c+1 /(1-a) \ln V_{t}-1.0 \ln w_{t}-(a /(1-a)) \ln r_{t}-(a /(1-a)) \ln J_{t} \\
& \equiv c+1.33 \ln V_{t}-1.0 \ln w_{t}-0.33 \ln r_{t}-0.33 \ln J_{t}
\end{aligned}
$$


if labor's share, (1-a), is 0.75 . This follows from rearranging equation (9). However, at first sight, there would seem to be a contradiction between equations (12) and (13) as the estimate of the elasticity of the demand for labor with respect to the real wage rate is $-\alpha$ and not -1.0 and the coefficients of $\ln \rho$ and $\ln r$ take opposite signs in the two equations. This is assuming $\ln J$ can be proxied by the time trend.

However, these discrepancies can easily be reconciled, given that equation (13) includes $\ln J$. We obtain from the identity the definition that:

$$
\ln L_{t} \equiv \ln (1-a)+\ln V_{t}-\ln w_{t}
$$

This is the same as the logarithm of labor's share, namely the logarithm of $(1-a)=$ $w L / V$, which has been rearranged. ${ }^{9}$

The identity given by equation (9.2) in logarithmic form and the Cobb-Douglas production function are given by:

$$
\ln V_{t} \equiv-a \ln a-(1-a) \ln (1-a)+a \ln r_{t}+(1-a) \ln w_{t}+a \ln J_{t}+(1-a) \ln L_{t}
$$

and

$$
\ln V_{t}=\ln A_{0}+\lambda \tau_{t}+\alpha \ln J_{t}+(1-\alpha) \ln L_{t}
$$

where again $\tau_{t}$ is a non-linear time trend.

\footnotetext{
${ }^{9} V \equiv w L+r J$ and $l \equiv w L / V+r J / V$ where $r J / V \equiv a$ and $w L / V \equiv(1-a)$. Taking logarithms of the last equation and rearranging gives equation (15).
} 
Consequently, $a=\alpha$ and $(1-a)=(1-\alpha)$ and

$$
\ln A_{0}+\lambda \tau_{t}=-a \ln a-(1-a) \ln (1-a)+a \ln r_{t}+(1-a) \ln w_{t}
$$

Rearranging equation (18) to give aln $r_{t}+(1-a) \ln w_{t}-$ alna $-(1-a) \ln (1-a)-\lambda \tau_{t}-\ln A_{0}$ $=0$ and adding it to the identity given by equation (15), gives:

$$
\ln L_{t} \equiv-\ln A_{0}+a \ln (1-a) / a+\ln V_{t}-a \ln w_{t}+a \ln r_{t}-\lambda \tau_{t}
$$

which is again nothing more than the identity. This is the same specification as the neoclassical demand for labor function, given by equation (12). The only difference is that, in the latter, the rate of "technical progress" is assumed to constant and proxied by a linear time trend (although there is nothing in neoclassical production function theory that states that this should always be the case). This assumption may cause a specification error that could reduce the goodness of fit and bias the coefficients. However, it can be seen from the identity that the elasticity of the demand for employment with respect to the real wage rate must equal the negative value of capital's factor share, and equal about -0.25 .

Table 2 illustrates this reasoning by estimating the various equations using data for US manufacturing over the period 1960 to 1993 . We did not undertake any of the usual diagnostics tests for stationarity of the variables because, as we are dealing with an identity, this issue is irrelevant. This is also true of other econometric estimation problems such as the exogeneity, or otherwise of the, regressors and the possibility simultaneous equation bias. The problem posed by the identity is not one of identification or econometric specification. It is far more fundamental. 
The results may be summarized as follows.

- Equation (i) is the result of estimating the full identity, equation (13). In the data set used, the average share of labor is 0.729 . The estimated values of coefficients are exactly what are to be expected from the identity.

- Equation (ii) merely incorporates a linear time trend into the identity, which in this context is an irrelevant variable. It makes little difference to the estimates.

- Equation (iii) drops $\ln J$ from the regression and gives a specification similar to the neoclassical labor demand function, equation (12). The coefficients are contrary what neoclassical production theory would lead to us to expect. In particular, the coefficient of Inr takes the wrong sign. But from the above discussion, we know the reason why: the linear time trend is not accurately proxying $a l n r_{t}+(1-a) l n w_{t}$. We could construct a more complex time trend as we did for Cobb and Douglas's original results. Nevertheless, we can make the point by explicitly including $a l n r_{t}+(1-a) I n w_{t}$ instead of $\tau_{t}$ in the regression. ${ }^{10}$

\footnotetext{
${ }^{10}$ An alternative approach, as we mentioned earlier, is to adjust the capital stock that has the effect of reducing the cyclical fluctuation in Inr.
} 
Table 2 Estimates of the 'Labor Demand Function', or Accounting Identity, for US Total Manufacturing; 1960-1993. Dependent Variable is InL.

\begin{tabular}{|c|c|c|c|c|c|c|}
\hline & $(i)^{a}$ & $(i i)^{b}$ & $(i i i)^{b}$ & $(i v)^{c}$ & $(v)^{f}$ & $(v i)^{f}$ \\
\hline Constant & $\begin{array}{l}-0.626 \\
(-2.32)\end{array}$ & $\begin{array}{l}-1.250 \\
(-6.76)\end{array}$ & $\begin{array}{r}-4.045 \\
(-13.23)\end{array}$ & $\begin{array}{l}-1.310 \\
(-0.77)\end{array}$ & $\begin{array}{l}-0.107 \\
(-0.07)\end{array}$ & $\begin{array}{l}1.549 \\
(0.89)\end{array}$ \\
\hline $\ln V$ & $\begin{array}{c}1.338 \\
(90.60)\end{array}$ & $\begin{array}{r}1.297 \\
(85.47)\end{array}$ & $\begin{array}{r}1.271 \\
(75.29)\end{array}$ & $\begin{array}{c}1.008 \\
(10.89)\end{array}$ & $\begin{array}{r}0.965 \\
(11.03)\end{array}$ & $\begin{array}{c}0.948 \\
(11.13)\end{array}$ \\
\hline Inw & $\begin{array}{c}-0.996 \\
(-48.27)\end{array}$ & $\begin{array}{c}-0.960 \\
(-51.13)\end{array}$ & $\begin{array}{c}-0.910 \\
(-35.14)\end{array}$ & - & $\begin{array}{l}-1.013 \\
(-8.40)\end{array}$ & $\begin{array}{c}-0.699 \\
(-3.30)\end{array}$ \\
\hline Inr & $\begin{array}{c}-0.349 \\
(-26.91)\end{array}$ & $\begin{array}{r}-0.325 \\
(-42.88)\end{array}$ & $\begin{array}{r}-0.307 \\
(-40.13)\end{array}$ & - & - & - \\
\hline $\ln (w / r)$ & - & - & - & $\begin{array}{l}-0.129 \\
(-4.29)\end{array}$ & - & - \\
\hline $\operatorname{lnJ}$ & $\begin{array}{c}-0.348 \\
(-47.70)\end{array}$ & $\begin{array}{r}-0.249 \\
(-12.41)\end{array}$ & - & - & - & - \\
\hline$t$ & - & $\begin{array}{l}-0.003 \\
(-5.57)\end{array}$ & $\begin{array}{c}-0.012 \\
(-17.39)\end{array}$ & $\begin{array}{l}-1.332^{d} \\
(-9.48)\end{array}$ & - & $\begin{array}{l}-0.007 \\
(-1.80)\end{array}$ \\
\hline $\bar{R}^{2}$ & 0.999 & 0.999 & 0.998 & 0.999 & 0.935 & 0.940 \\
\hline SER & 0.002 & 0.002 & 0.003 & 0.002 & 0.016 & 0.015 \\
\hline$D W$ & 1.498 & 2.445 & 1.936 & $0.299^{e}$ & 1.916 & 1.812 \\
\hline
\end{tabular}

Notes: a Exact AR(1) Newton-Raphson iterative method.

$b$ Exact $A R(2)$ Newton-Raphson iterative method.

$c$ OLS, long-run elasticities; one-year lags of $I n L, \ln V$, and $a l n r+(1-a) / n w$.

$d$ Coefficient of alnr $+(1-a) / n w$, which is substituted for the linear time trend

e Durbin's h-test.

$f \quad$ Long-run elasticities; one-year lag of $\ln V$ and Inw. Exact AR(1) NewtonRaphson iterative method.

Sources: NBER Manufacturing Database, OECD database, Felipe and McCombie (2009, p. 158)

Memorandum item: Average share of labor $=0.729$. 
- Equation (iv) reports the results of this specification (but where we constrain the coefficients of $I n w$ and $I n r$ to take equal and opposite signs). This gives us the expected estimates that have been taken as representing the coefficients of a neoclassical labor demand function. (See the classic study by Clark and Freeman, 1980).

We also confirmed these results using data from the US Bureau of Labor Statistics and the rental price of capital (rather than the rate of profit), for the period 1948 2005 and, not surprisingly, got virtually identical results.

An alternative method is to estimate the marginal revenue product curve for labor. For the constant elasticity of substitution (CES) production function, this is specified as:

$$
\ln L_{t}=-(1-\sigma) \ln A_{0}+\sigma \ln (1-a)+\ln V_{t}-\sigma n w_{t}-(1-\sigma) \lambda t
$$

where $\sigma$ is the elasticity of substitution and (1-a) is labor's share. See Lewis and McDonald (2002) for a formal derivation.

As $\sigma$ tends to unity, so equation (20) will tend to equation (15) which is the CobbDouglas specification. In this latter case, the elasticity of employment with respect to the wage rate is - $\alpha$ and may be calculated from the estimate of $(1-\alpha)$ obtained from the intercept. Under both the usual neoclassical assumptions and from the identity, the elasticity will equal - $a$. In the case of the CES production function, it is capital's share multiplied by the elasticity of substitution. It can be seen that an increase in the real wage, ceteris paribus, will result in a decline in employment, which is the crucial neoclassical result. As factor shares are constant, we first 
estimated equation (15) and the results are reported in Table 2, equation (v). It gives a very good statistical fit which is, however, not surprising as again the equation is merely picking up the underlying accounting identity.

In equation ( $V I)$ a time trend is included, which biases the coefficient of Inw downwards, which could be erroneously interpreted as a CES labor demand function with an elasticity of substitution of less than unity. (See Lewis and MacDonald, 2002, for a similar result using Australian data, but interpreted along neoclassical lines.)

Thus, to summarize the results of Table 2, Equation (i) is merely the result of estimating the accounting identity, expressed in logarithmic form and rearranged. The value of the estimates of the coefficients are known a priori because they are merely reflecting the size of the factor shares in total output. The only reason why there is not perfect multicollinearity is that the shares show some variation over time. The other equations have been interpreted as production relationships reflecting the marginal productivity conditions. Previous studies have taken such results as confirming the marginal productivity theory of distribution. However, it has been shown in this paper that the reason that these estimations get such good fits is simply because they use value data and are merely capturing the underlying accounting identity. The specifications could only test production function relationships if physical data are used, for which aggregate data by definition are not available, and not constant price value data.

\section{The Constancy of Factor Shares}

The observed approximate constancy of the factor shares, while compatible with the existence of an aggregate production function, cannot be taken as in any way providing evidence of its existence. 
We may demonstrate this straightforwardly. Let us assume that there is no welldefined aggregate production function because of the usual aggregation problems. Manufacturing firms are assumed to set their prices as a proportionate mark-up $\left(1+\pi_{i}\right)$ on unit labor costs (Lee, 1998). Strictly speaking, the mark-up should be on total unit costs but this does not seriously affect our argument. The price of output and the total value produced by the th firm are given by

$$
p_{i}=\left(1+\pi_{i}\right)\left(w_{i}^{n} L_{i} / Q_{i}\right)
$$

and

$$
p_{i} Q_{i}=V_{i}=\left(1+\pi_{i}\right) w_{i}^{n} L_{i}
$$

where $w_{i}^{n}$ is the nominal wage rate.

If the mark-up and the real wage rate are roughly constant across firms, equation (22) can be written in real terms for the total industry as:

$$
\sum p_{i} Q_{i}=V_{I N D}=(1+\pi) w \sum L_{i}=(1+\pi) w L_{I N D}
$$

Consequently, labor's share is constant and in aggregate value terms is given by:

$$
1 /(1+\pi)=(1-a)=w L_{I N D} / V_{I N D}
$$

and taking logarithms and rearranging gives equation (15).

Anadyke-Danes and Godley (1989) adopt this approach in a series of mark-up models that they use in simulation analyses. (See Lavoie, 2008.) They, however, use prices and, implicitly, physical output. The simplest model, although not the 
most realistic, is to assume that prices are determined by a mark-up on current and lagged labor unit costs:

$\ln p_{t}=\ln (1+\pi)+\varphi\left(\ln w_{t}^{n}+\ln L_{t}-\ln Q_{t}\right)+(1-\varphi)\left(\ln w_{t-1}^{n}+\ln L_{t-1}-\ln Q_{t-1}\right)$

where $\varphi$ equals 0.75 .

The reason for the weights $\varphi$ and $(1-\varphi)$ is that Anadyke-Danes and Godley assume that three-quarters of sales are from current production and one-quarter from inventories produced in the last period. Firms, thus, adopt a historic cost pricing policy. They generate hypothetical data by assuming that wages, output and employment grow at 7 per cent, 5 per cent and 1 per cent per annum, respectively, together with small random elements.

They run a typical neoclassical labor demand regression and obtain the following regression result:

$$
\ln L_{t}=1.3-0.94 \ln w_{t}+0.12 \ln L_{t-1}+0.73 \ln Q_{t}+0.01 t
$$

or the equilibrium relationship:

$$
\ln L_{t}=1.48-1.07 \ln w_{t}+0.83 \ln Q_{t}+0.01 t
$$

However, the level of employment is, by construction, independent of the real wage, and so the negative relationship between the logarithm of the two variables has no implications about causality, contrary to the usual neoclassical interpretation. Thus, these equations cannot be interpreted as giving any support to 
the neoclassical model. Prices are determined by a cost-based principle and not by marginal costs.

\section{Conclusions}

In this paper, we have shown how the use of constant-price value data and the existence of an accounting identity preclude the testing of the neoclassical marginal productivity theory of distribution.

We present some regression results that illustrate the theoretical argument that what may seem to be behavioural relationships based on the marginal productivity theory turns out to be nothing but transformations of an underlying accounting identity.

In his survey of labor demand functions, Hamermesh (1993, p.92) concludes that "if one were to choose a point estimate for this parameter [the elasticity of labor demand, holding output constant], 0.30 would not be far wrong". This is roughly the same figure Douglas (1934) found and is consistent with the Cobb-Douglas production function where labor's share is 0.7. As Hamermesh (1993, p.92, omitting a footnote) further remarks, "the immense literature that estimates the constant-output demand elasticity for labor in the aggregate has truly led us 'to arrive where we started and know the place for the first time' ". ${ }^{11}$ We have shown why this must be the case, and why we know what the estimates must be before a single regression has been run.

\footnotetext{
${ }^{11}$ The quotation is from T.S. Eliot's poem, "Little Gidding".
} 
It has often been asserted that the fact that factors are paid their marginal products provides a justification that income ought to be distributed in this fashion.

Even if it is considered that this is inequitable, it nevertheless is taken to represent the baseline where those who make the greatest contribution to output, are giving up part of their justly earned remuneration for the "greater good". However, as these indirect empirical tests cannot be taken as supporting the position that workers and capitalists receive their marginal products, then there is all the more reason to challenge the existing distribution of income.

\section{Authors' Notes}

The authors thank the three referees of this journal for their most helpful comments which have led to a clarifications and extensions of the argument.

Disclaimer: The views expressed in this article are the authors' and not necessarily those of the Asian Development Bank, those of its Executive Directors, or the member countries that they represent.

\section{Declaration of Conflicting Interests}

The authors declared no potential conflicts of interest with respect to research, authorship, and/or publication of this article.

\section{Funding}

The authors received no financial support for the research, authorship and/or publication of this article. 


\section{References}

Anadyke-Danes, M., and Godley, W. 1989. Real wages and employment: a sceptical view of some recent empirical work, Manchester School of Economics and Social Studies, 57 (2): 172-187.

Arrow, K. J., Bernheim, B. D. Feldstein, M. S. McFadden, D. L., Poterba, J. M., and R.M. Solow, R. M. 2011. 100 years of the American Economic Review: the top 20 articles. American Economic Review, 101(1): 1-8.

Blaug, M. 1980. The methodology of economics: or, how economists explain. Cambridge: Cambridge University Press.

Clark, J.B. 1899. The distribution of wealth. New York: Macmillan.

Clark, K.B., and R. B. Freeman. 1980. How elastic is the demand for labor? Review of Economics and Statistics, 62(4): 509-520.

Cobb, C.W., and P.H. Douglas.1928. A theory of production. American Economic Review (Supplement), 18(1): 139-165.

Douglas, P.H. 1934. The theory of wages. New York: Macmillan.

Douglas, P.H. 1948. Are there laws of production?. American Economic Review, 38(1): 1-41. 
Douglas, P. H. 1976. The Cobb-Douglas production function once again: its history, its testing, and some new empirical values. Journal of Political Economy, 84(5): 903-915.

Estrin, S., and D. Laidler. 1995. Introduction to microeconomics. Hemel Hempstead: Harvester Wheatsheaf.

Felipe, J., and F.G. Adams. 2005. "A theory of production". The estimation of the Cobb-Douglas Function: a retrospective view, Eastern Economic Journal, 31(3): 42746.

Felipe, J., and J.S.L. McCombie. 2009. Are estimates of labour demand functions mere statistical artifacts? International Review of Applied Economics, 23(2): 147-168.

Felipe, J. and J.S.L. McCombie. 2013. The aggregate production function and the measurement of technical change. "Not even wrong", Cheltenham: Edward Elgar.

Ferguson, C.E. 1969. The neoclassical theory of production and distribution.

Cambridge: Cambridge University Press (reprinted 1971).

Ferguson, C.E. 1971. Capital theory up to date: a comment on Mrs. Robinson's article, Canadian Journal of Economics, 4(2): 250-254.

Fisher, F. M. 1971. Aggregate production functions and the explanation of wages: a simulation experiment, Review of Economics and Statistics. 53(4): 305-325.

Fisher, F. M. 1992, Aggregation. Aggregate production functions and related topics. ed. J. Monz, London: Harvester Wheatsheaf. 
Fisher, F.M. 2005. Aggregate production functions - a pervasive, but unpersuasive, fairytale. Eastern Economic Journal, 31(3): 489-491.

Friedman, M. 1953. The methodology of positive economics, In Essays in Positive Economics, Friedman M. pp. 3-43. Chicago: University of Chicago Press.

Hamermesh, D.S. 1993. Labor demand. Princeton, NJ: Princeton University Press.

Harcourt, G.C. 1976. The Cambridge controversies: old ways and new horizons - or dead end?. Oxford Economic Papers, 28(1): 25-65.

Hicks, J. R. 1932, The theory of wages. London: Macmillan.

Hoover, K. D. 2012. Applied intermediate macroeconomics. Cambridge: Cambridge University Press,

Kuhn, T. 1970. The structure of scientific revolutions. Chicago and London: University of Chicago Press ( $2^{\text {nd }}$ edition).

Lavoie, M. 2008., Neoclassical empirical evidence on employment and production laws as artefact .Research on Banking International and National Systems or Networks, Working Paper no. 09-09.

Lee, F.S. 1998. Post-Keynesian price theory. Cambridge: Cambridge University Press. 
Lewis P.E.T and G. MacDonald. 2002. The elasticity of demand for labour in Australia. Economic Record, 78(2400: 18-30.

McCombie, J.S.L. 1998. 'Are There Laws of Production?': an assessment of the early criticisms of the Cobb-Douglas production function, Review of Political Economy, 10:2, 141-173,

Mankiw, N.G. and M.P. Taylor. 2008 Macroeconomics. New York: Worth Publishers (European edition)

Mendershausen, H. 1938. On the significance of Professor Douglas' production function. Econometrica, 6(2): 143-53. [A correction, ibid. 7: 1938.]

Moseley, F. 2015. The marginal productivity theory of capital in intermediate microeconomics textbooks: a critique. Paper presented at the session Debating Marginal Productivity at the ASSA Conference, Philadelphia, US, January 2014 and this Journal.

Phelps Brown, E. H. 1957. The Meaning of the Fitted Cobb-Douglas Function. Quarterly Journal of Economics, 71(4): 546-560.

Robinson, J.V. 1953-54. The production function and the theory of capital. Review of Economic Studies, 21(2): 81-106.

Shaikh, A. 1974. Laws of production and laws of algebra: The Humbug production function. Review of Economics and Statistics, 56(1): 114-120. 
Simon, H. A. 1979. On parsimonious explanations of production relations.

Scandinavian Journal of Economics, 81(4): 459-474.

Simon, H. A., and F. K.Levy. 1963. A Note on the Cobb-Douglas function. Review of Economic Studies, 30(2): 93-4.

Solow, R. M. 1957. Technical change and the aggregate production function, Review of Economics and Statistics, 39(3): 312-320.

Solow, R.M. 1988. Growth theory and after. American Economic Review, 78(3): 307-317.

Thurow, L.C. 1975. Generating inequality. New York: Basic Books.

\section{Author Biographies.}

Jesus Felipe is Advisor in the Office of the Chief Economist, Economics and Research Department, Asian Development Bank, Manila, Philippines.

John McCombie is Professor of Regional and Applied Economics, University of Cambridge, Director of the Cambridge Centre for Economics and Public Policy and Fellow in Economics, Downing College, Cambridge. 


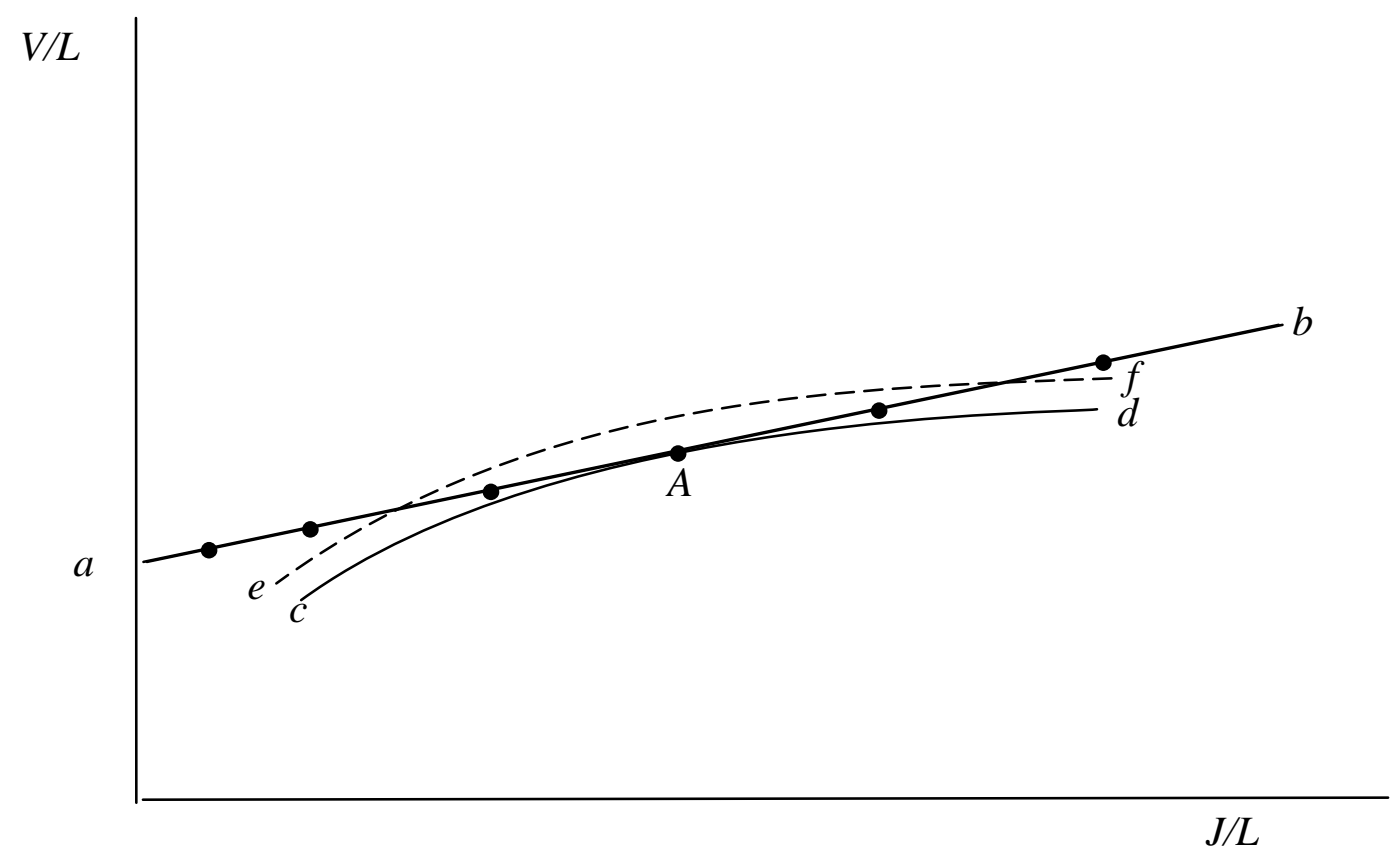

Figure 1. The Cobb-Douglas Approximation to the Linear Accounting Identity 